\title{
Effect of slaughter technique on bleed-out, blood in the trachea and blood splash in the lungs of cattle
}

\author{
B. Agbeniga \& E.C. Webb \\ Department of Animal and Wildlife Sciences, University of Pretoria, 0002 Pretoria, South Africa
}

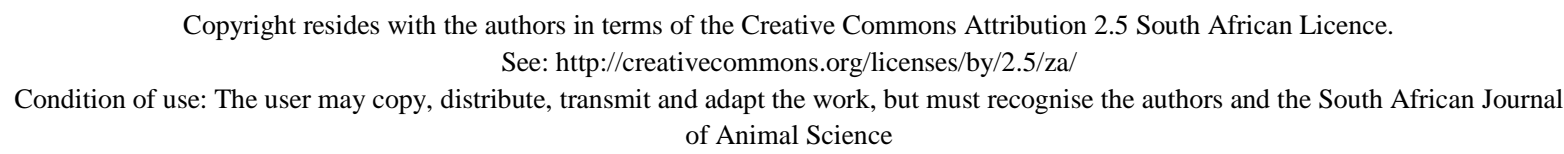

\begin{abstract}
The South African Animal Protection Law, which requires animals to be stunned before slaughter, allows certain exemptions to accommodate religious slaughter. The supporters of the Jewish method of slaughter (Shechita), in which animals are slaughtered without pre-stunning, claim that the bleed-out and some quality parameters are better than when the animals are stunned before slaughtering. In this study, the percentage blood loss (BL\%), presence (\%) of blood in the trachea (BLT\%) and blood splash \% in the lungs (BS\%), between the Shechita (Kosher) group and the conventionally slaughtered group of cattle were compared. Results showed no significant difference between the two treatment groups in terms of blood loss, although the conventional group had a higher bleed-out. However, there were significant differences in the presence of blood in the trachea and blood splash in the lungs, with the Kosher group having the highest percentages of these quality defects. Out of 170 animals examined for Kosher, 93\% had blood lining the trachea, ranging from one to over 50\%. From the 141 animals examined for the conventionally-slaughtered group, $97 \%$ had no blood lining the trachea while the remaining $3 \%$ had less than $10 \%$ blood lining the trachea. Furthermore, $65 \%$ of animals slaughtered in the Kosher way had blood splash ranging from $5 \%$ to over $50 \%$, while the conventional group had only $0.7 \%$ incidence of blood splash in the lungs. These results show that slaughtering animals without stunning do not improve bleed-out, but increase blood in the trachea and blood splash in the lungs.
\end{abstract}

Keyword: Blood loss, conventional slaughter, Kosher slaughter (Shechita), sticking, stunning

\#Corresponding author: Edward.webb@up.ac.za

\section{Introduction}

In South Africa there has been a long contention between the Livestock Welfare Coordinating Committee (LWCC) and the Jewish body for Kosher (Beth-din) about the manner in which animals are being Kosher-killed in the so-called rotating box. The animals are inverted at an angle of about $110^{\circ}$ before sticking, and the time animals are stunned post-cut (NSPCA, 2007; www.nspca.co.za; LWCC, 2010 unpublished). Part of the reason emanates from new evidence that animals (in this case cattle) do experience pain and distress for up to 60 seconds or longer after the incision before becoming unconscious (Mellor et al., 2009). Another reason is the possibility of undue stress before slaughter (Grandin, 1988; Dunn, 1990). Daly et al. (1988) also found that the time before the brain loses responsiveness was significantly longer in cattle following Shechita (mean of 55 seconds for visual evoked response and 77 seconds for somatosensory response) compared to the captive bolt stun method, which is immediate. The Farm Animal Welfare Council (FAWC, 2003) in the United Kingdom also concluded that pre-slaughter handling and delayed or absence of stunning in religious slaughter can cause stress and present welfare problems. On this basis, the FAWC recommended that the exemption for religious slaughter be repealed (FAWC, 2003).

One of the major concerns of the Jewish communities is that the bleed-out of animals stunned before sticking is impeded as a result of neurological, muscular and cardiovascular changes caused by stunning. The reason for this claim comes from the Jewish biblical laws (Levinger, 1995) which prohibit consumption of blood. According to the law, blood must not be consumed either in exsanguinated form or in the meat, and 
consequently, they require an effective, total bleed-out. Poor bleeding can also affect the appearance and visual acceptability of a carcass (Gregory, 2004). Several researchers (Grifith et al., 1985; Kallweit et al., 1989; Anil et al., 2004; 2006) found no difference in blood loss between animals slaughtered by Shechita or conventional methods. Another recent cause for concern in Shechita is the presence of blood in the respiratory tract due to aspiration and the incidence of blood splash especially in the lungs. (Webster, 1994; Gregory et al., 2008). Blood aspiration is an indicator of stress as the animal agonises while trying to breathe after the neck has been cut, while blood splash downgrades the lungs, which is consumed by many people in this part of the world. Some of the lungs were condemned because of the high level of blood engorgement which also reduces the carcass quality. The work of Gregory et al. (2008) showed that a high percentage of animals slaughtered without pre-stunning had high percentage of blood lining in the respiratory tract and the upper bronchi. They argued that blood could have been aspired through the cut trachea and also, a rupture of the alveolar-capillary network could have occurred during agonal respiration. In their work they referred to blood splash as lobular haemorrhage which was present in $63 \%$ of the animals examined for religious slaughter.

The aim of this study was to compare the bleed-out, occurrence of blood in the trachea and blood splash in the lungs between the Jewish method (Shechita) and conventional slaughtering methods due to the concerns about the effects of slaughter method on carcass quality, animal welfare and subsequent economic implications. The parameters evaluated were: bleed-out, presence of blood in the trachea and the incidence of blood splash in the lungs.

\section{Materials and Methods}

The trial was conducted at a high throughput abattoir during July 2010. A total of 311 animals were analysed for blood loss and the presence of blood in the trachea. One hundred and seventy were assigned for Kosher while 141 were assigned for conventional slaughter. Pre-slaughter conditions were assessed to ensure that animals were not unnecessarily stressed pre-slaughter, as this can affect meat and carcass qualities (Gregory, 1998). Animals were treated humanely and animals from different farms were penned separately to avoid fight and stress. The animals had about 12 hours overnight lairage time with access to water but without feed. Three hundred and eleven typical crossbred feedlot cattle, weighing on average $400 \mathrm{~kg}$, were randomly selected for this trial. The age of the bulls were representative of the " $A$ " and "AB" age groups, which represent more than $80 \%$ of feedlot cattle. Cattle were assigned to two treatments: Kosher and conventional groups.

Kosher slaughter was done using the American Society for Prevention of Cruelty against Animals (ASPCA) specially designed box in which the animals stand upright. It is fitted with a hydraulic chin lift that lifts the head upwards and extends the neck for the cut; belly plate to raise the animal for stability and a rear pusher to reduce the struggle of the animal with a firm restraint (Grandin \& Regenstein, 1994; Shragge \& Price, 2004). The Shochet then sticks the animal with a sharp knife of about $40 \mathrm{~cm}$ long. The cut is made upwards and across the ventral part of the neck whilst the animal is restrained. This is done swiftly within one second in accordance with the Talmudic standards (Levinger, 1995). While in this position, animals are then stunned with a 0.22 calibre penetrative captive bolt gun in the frontal position of the head 20 seconds after sticking, to render them unconscious (Gregory, 1998). The carcasses are then hoisted by the hind leg and allowed to bleed out for about eight minutes before being electrically stimulated. The weight after bleeding (WAB) is then recorded in kg with a digital scale for each carcass, before evisceration and carcass splitting. Percentage blood loss was expressed as a percentage of the live weight. It was obtained by subtracting the weight after bleeding (WAB) from the weight before slaughter (WBS) (live weight) and multiplying it by 100 (Anil et al., 2004; 2006).

Following carcass splitting, the lungs of the animals slaughtered by Kosher method went through the conventional bedika procedure (Gregory et al., 2008). The bedika procedure involves the examination of the internal organs to ensure that the animal's health meets the Talmudic standards of wellness at the time of slaughter. However, lung examination stands as the focal point of bedika. It seeks to identify evidence of pleural adhesions that might, for example, indicate a punctured lung. The lungs are filled with air and submerged in water as a test of pulmonary integrity. Air-tightness indicates an absence of organ wall damage which is sufficient for Kosher certification and is based on the belief that any systemic mobidity in an animal would be evident in the lungs (Levinger, 1995; Shragge \& Price, 2004). After this procedure, the lungs and tracheas were removed to subjectively score the amount of blood in the trachea (BLT) and blood splash (BS) 
in the lungs. This was done in accordance with the works of Gregory et al. (2008). The BLT was scored by cutting out about $25 \mathrm{~cm}$ of the trachea and opening it along its length up to the upper bronchi with a sharp knife to observe and quantify the amount of blood. Bright-red blood-tinged foam was also observed in some of the tracheas from the Kosher-slaughtered animals. The scoring was done in the following way: $0=$ no blood present; 1 = some blood present but less than $10 \%$ of the inner surface area of the trachea; $2=$ blood covered $11 \%-50 \%$ of the inner surface; $3=$ blood covered over $50 \%$ of the inner surface area.

Blood splash in the lungs was visually and subjectively scored from $0 \%$ to over $50 \%$. It was done in the following way: $0=$ no blood; $1=$ blood covered between $1 \%-10 \% ; 2=$ blood covered from 11 to over $50 \%$. The amount of splash could easily be seen as dark patches as they were scattered over the two lobes of lungs. Some were split open with a knife to observe the extent of the splash and to ascertain the freshness of the blood. In total, 170 sets of lungs and tracheas were observed and scored for Kosher while 141 were scored for conventional slaughter.

The conventional slaughter was done by stunning with a pneumatic captive bolt gun which uses compressed air (Anil et al., 2002). The animals were restrained in a v-shaped metal box with an open top and with a rear gate to prevent the animals from struggling or moving backwards after entering the box. They were restrained in an upright position and the shot was delivered to the forehead. They were then released from the box, hoisted and cut to bleed on the bleeding rail almost immediately. Every other procedure after this was similar to the Kosher except that the lungs did not go through the bedika procedure. The tracheas and lungs were also scored as for Kosher. Percentage blood loss was also obtained as for Kosher.

Statistical analyses was performed using SAS (2008). Analyses of variance were done using the general linear model (GLM) procedure to analyse the percentage blood loss. Percentage blood in the trachea and percentage blood splash was analysed using the Proc Logistic procedure and using type 3 analyses of variance and Chi square to determine the $P$ values. Proc Frequency procedure was used to determine the frequencies and percentages.

\section{Results and Discussion}

The two slaughter methods did not differ $(P>0.05)$ in terms of blood loss. This accords with Anil et al. (2004) on sheep and Anil et al. (2006) on cattle, who found no differences $(P>0.05)$ in sheep and cattle slaughtered with or without stunning. Additionally, they also recorded more blood loss in the captive bolt stunned group (conventional group) compared to the non-stun groups. Anil et al. (2004) used the Muslim method, which is similar to Shechita, as the animals were slaughtered without pre-stunning. They also found no difference in the packed cell volumes between the two slaughter methods. In the present study, the mean percentage blood loss for the Shechita group was $2.34 \pm 0.58 \%$ while that of the conventional group was $2.42 \pm 0.67 \%$.

The two slaughter groups differed $(P<0.0001)$ in terms of the presence of blood in the trachea, with the Kosher group having a much higher percentage of occurrence of blood in the trachea for codes 1, 2 and 3 (Table 1). In addition, $76 \%$ of the animals slaughtered by Kosher method had blood in the upper bronchi while none of the conventionally slaughtered group had blood in the upper bronchi. Thirty-two percent of the tracheas examined for Kosher slaughter also had bright-red, blood-tinged foam while none of the tracheas examined for conventional slaughter had blood-tinged foam.

Concerning blood splash, the same carcasses and numbers used for the analyses of blood loss and presence of blood in the trachea were used to subjectively quantify the percentage of blood splash in the lungs. As shown in Table 2, analyses reveal a significant difference $(P<0.0001)$ between the Kosher and the conventionally slaughtered group. Sixty-five percent of the lungs from the Kosher-slaughtered animals had blood splash ranging from 5\% to over 50\% while only one of the 141 carcasses examined for the conventional slaughter group had about $10 \%$ splash.

There have been reports of more efficient exsanguinations after Shechita compared to using captive bolt, pre-cut (Miller, 1952; Levinger, 1976; 1995). It was claimed that blood loss can be impeded by stunning as a result of neurological, muscular and cardiovascular changes caused by stunning. The authors further claimed that the deep respiratory movement and gasping after Shechita makes exsanguination better and that because contraction occurs towards the end of the bleeding, the remaining blood is forced out of the vessels. 
Table 1 Frequencies of occurrence of blood in the trachea for the two slaughter methods

\begin{tabular}{|c|c|c|c|c|}
\hline Code $^{1}$ & Frequencies & Conventional & Kosher & Total \\
\hline \multirow[t]{3}{*}{0} & Freq & 137 & 11 & 148 \\
\hline & Row \% & 92.6 & 7.4 & \\
\hline & Column \% & 97.2 & 6.5 & \\
\hline \multirow[t]{3}{*}{1} & Freq & 4 & 61 & 65 \\
\hline & Row \% & 6.2 & 93.8 & \\
\hline & Column \% & 2.8 & 35.9 & \\
\hline \multirow[t]{3}{*}{2} & Freq & 0 & 75 & 75 \\
\hline & Row \% & 0.0 & 100 & \\
\hline & Column \% & 0.0 & 44.1 & \\
\hline \multirow[t]{3}{*}{3} & Freq & 0 & 23 & 23 \\
\hline & Row \% & 0.0 & 100.0 & \\
\hline & Column \% & 0.0 & 13.5 & \\
\hline Total & & 141 & 170 & 311 \\
\hline
\end{tabular}

Table 2 Frequencies of blood splash in the lungs for the two slaughter methods

\begin{tabular}{|c|c|c|c|c|}
\hline Code $^{1}$ & Frequencies & Conventional & Kosher & Total \\
\hline \multirow[t]{3}{*}{0 (no blood) } & Freq. & 140 & 59 & 199 \\
\hline & Row \% & 70.4 & 29.7 & \\
\hline & Column \% & 99.3 & 34.7 & \\
\hline \multirow[t]{3}{*}{1 (1\%-10\% blood) } & Freq. & 1 & 43 & 44 \\
\hline & Row \% & 2.3 & 97.7 & \\
\hline & Column \% & 0.7 & 25.3 & \\
\hline \multirow[t]{3}{*}{2 (11+ \% blood) } & Freq & 0 & 68 & 68 \\
\hline & Row \% & 0.0 & 100.0 & \\
\hline & Column \% & 0.0 & 40.0 & \\
\hline Total & & 141 & 170 & 311 \\
\hline
\end{tabular}

${ }^{1} 0$ = no blood; 1 = blood covered between $1 \%$ - 10\%; 2 = blood covered from 11 to over $50 \%$.

Slaughter methods differed largely $(P<0.05)$ in terms of the percentage BLT. Ninety-three \% of the animals slaughtered by Kosher technique had blood lining the trachea, ranging from less than $10 \%$ to over $50 \%$, while $97 \%$ of the conventionally slaughtered group had no blood lining the trachea. In the past, concerns were raised about blood aspiration in cattle slaughtered in the inverted position for ritual slaughter when the cut was made (Blokhuis et al., 2004). This study shows that animals slaughtered in the upright position without pre-stunning exhibited similar behaviour. This result is also similar to Tsokos et al. (2004) when humans were decapitated without prior stunning. Blood was found in the respiratory tracts due to aspiration. Gregory et al. (2008) indicated the likelihood of the activation of laryngeal receptors as the cause. The presence of the blood-tinged foam indicates that blood has been expelled from the lungs following churning in the alveoli through breathing actions before reaching the exsanguinated state. It is speculated that the redness of the foam could be caused by the blood entering from the pulmonary capillary barrier or by aspiration with air taken in through the severed trachea. Observations at the abattoir indicate that blood was 
inspired through the cut end of the trachea due to agonal respiration in the Shechita group. Most of the animals struggled to continue breathing before being stunned by the captive bolt.

Concerning percentage blood splash in the lungs, the scoring was done in estimated percentages based on visual examination of the extent of the splash in the two lobes of lungs. The Shechita and the conventional slaughter group differed $(P<0.05)$ with the Kosher group having a much higher mean percentage compared to the conventional group. Grandin \& Regenstein (1994) noted that blood splash is a severe problem in the Kosher slaughter method due to agitation and too much pressure on the body such as belly lift and rear pusher especially in grain fed cattle. Blood splash is usually found in the diaphragm, forequarters, heart, lungs and gall bladder (Meat \& Livestock Australia, 1997). In the present study, only blood splashes in the lungs were detected which is similar to results obtained by Gregory et al. (2008), although this was referred to as lobular haemorrhage. They found $63 \%$ lobular haemorrhage and $47 \%$ of the lungs affected. As Gregory et al. (2008) reported in their work, the splash could have been caused by the rupture of alveolar-capillary interconnections in the lungs or blood was drawn into the lungs from the severed trachea as the animals tried to breath (Swatland, 1984). Furthermore, it could be that the lungs were unable to drain the blood from caudal venous return because at that time, the animals were progressing to the exsanguinated state by the time respiratory agonal spasm sets in.

\section{Conclusion}

This study showed that bleed-out in slaughtered cattle is not adversely affected by captive bolt stunning nor improved by Shechita. Hopefully, these findings will help promote or encourage stunning before or immediately after Shechita to stop the suffering of the animals. Based on the percentage blood in the trachea and blood splash in the lungs, the results of this study calls for a grave concern from quality, welfare and economic perspectives. More studies are needed to check the effects of immediate post-cut stun and to ascertain more underlying causes of these defects in Kosher slaughter. Similar studies are also recommended for small ruminants and other livestock.

\section{Acknowledgement}

This work was funded by the Red Meat Research and Development of South Africa (RMRD-SA).

\section{References}

Anil, M.H., Love, S., Helps, C.R. \& Habour, D.A., 2002. Potential for carcass contamination with brain tissue following stunning and slaughter in cattle and sheep. Food Control 13, 431-436.

Anil, M.H., Yesildere, T., Aksu, H., Matur, E., Mckinstry, J., Erdogan, O., Hughes, S. \& Mason, C., 2004. Comparison of religious slaughter of sheep with methods that include pre-slaughter stunning and lack of differences in exanguination, packed cell volume and meat quality parameters. Animal Welfare 13, 387-392.

Anil, M.H., Yesildere, T., Aksu, H., Matur, E., Mckinstry, J.L., Weaver, H.R., Erdogan, O., Hughes, S. \& Mason, C., 2006. Comparison of Halal slaughter with captive bolt stunning and neck cutting in cattle: exanguination and quality parameters. Animal Welfare 15, 325-330.

Blackmore, D.K., 1984. Differences in behaviour of sheep and calves during slaughter. Res. Vet. Sci. 37, 223-226.

Blokhuis, H.J., Roth, B., Holst, S., Mohan, R. \& Terlouw, C., 2004. Welfare aspects of animal stunning and killing methods. Scientific Report of the Scientific Panel for Animal Health and Welfare on a request from the Commission related to welfare aspects of animal stunning and killing methods, (EFSA-Q2003-093, p. 24).

Dally, C.C., Kallweit, E. \& Ellendof, F., 1988. Cortical function in cattle during slaughter slaughter: conventional and captive bolt stunning followed by exanguination compared to Shechita. Vet. Rec. 122, 325-329.

Dunn, C.S., 1990. Stress reactions of cattle undergoing ritual slaughter using two methods of restraint. Vet. Rec. 126, 522-525.

FAWC, 2003. Reports on the welfare of farm animals at slaughter or killing, part 1: Red Meat Animals. Farm Animal Welfare Council (FAWC), London, UK. - 1993 - MAFF, Tolworth, UK. 
Grandin, T. \& Regenstein, J.M., 1994. Religious slaughter and animal welfare: a discussion for Meat Scientists. In: Meat Focus International. CABI, Wallingford, UK. pp. 115-123.

Gregory, N.G., 1998. Animal Welfare and Meat Science. CABI Publishing, Oxford, UK.

Gregory, N.G., 2004. Exanguination: Encyclopedia of Meat Science. Oxford Academic. pp. 458-460.

Gregory, N.G., Von Wenzlawowicz, M. \& Von Holleben, K., 2008. Blood in the respiratory tract during slaughter with and without stunning in cattle. Meat Sci. 82, 13-16.

Grifith, G.L., Mc Grath, M., Softly, A. \& Jones, C., 1985. Blood content of broiler chicken carcasses prepared by different slaughter methods. Vet. Rec. 117, 382-382.

Kallweit, E., Ellendorf, F., Daly, C. \& Smidt, D., 1989. Physiological reactions during slaughter of cattle and sheep with and without stunning. Deutsh Tierarztl Wochenschr. 96, 89-92.

Levinger, I.M., 1976. Physiological and general medical aspects of Shechita. In: Munk, M.L. \& Munk, E. (Shechita), Gur Aryeh Publications, Jerusalem, Isreal. pp. 101-214.

Levinger, I.M., 1995. Shechita in the light of the year 2000. Critical view of the scientific aspects of methods of slaughter and Shechita. Maskil, L., David: Jerusalem, Isreal.

Livestock Welfare Coordinating Committee of South Africa (2010) (unpublished).

Meat and Livestock Australia, 1997. In: Meat Technology Update. Food Science Australia, Tingalpa DC QLD 4173.

Mellor, D.J., Gibson, T.J. \& Johnson, C.B., 2009. A re-evaluation of the need to stun calves prior to slaughter by ventral neck incision: An introductory review. N. Z. Vet. J. 57, 74-76.

Miller, A.R., 1952. Meat Hygiene. Lea and Fabiger, Philadelphia, USA.

SAS, 2008. Statistical Analysis System user's guide $\left(2^{\text {nd }}\right.$ ed) (Version 9.2). SAS Institute Inc., Cary, North Carolina, USA.

Shragge, J.E. \& Price, M.A., 2004. Religious slaughter: Encyclopedia of Meat Science. Oxford Academic Press, UK. pp. 1162-1167.

Swatland, H.J., 1984. Structure and Development of Meat Animals. Prentice-Hall, Inc., Engelwood Cliffs, New Jersey, 07632, UK.

Tsokos, M., Turk, E.E., Uchigasaki, S. \& Puschel, K., 2004. Pathologic features of suicidal decapitations. Forensic Sci. Int. 139 (2), 95-102.

Warris, P.D., 1978. Factors affecting residual blood content of meat. Meat Sci. 2, 155-159.

Webster, J., 1994. A cool eye towards Eden. In: Animal Welfare. Oxford, UK: Blackwell Science, UK. 